\title{
Microwave radiation influence on the thermal and spectroscopic properties of Na-birnessite-type material
}

\section{(Influência da radiação por micro-ondas nas propriedades termais $e$ espectroscópicas de Na-birnessita)}

\author{
T. C.C. Lavra', L.A.Silva ${ }^{2}$, K. S. B. Cavalcante ${ }^{2}$, K. L. L. Marinho ${ }^{3}$, B.A.M. Figueira ${ }^{3 *}$, J. M. Rivas Mercury ${ }^{1}$ \\ ${ }^{I}$ Instituto Federal do Maranhão, Programa de Pós-Graduação em Engenharia de Materiais, São Luís, MA, Brazil \\ ${ }^{2}$ Universidade Federal do Maranhão, Programa de Pós-Graduação em Energia, São Luís, MA, Brazil \\ ${ }^{3}$ Universidade Federal do Oeste do Pará, Programa de Pós-Graduação em Sociedade, Ambiente e Qualidade de \\ Vida, R. Vera Paz, s/n, 68035-110, Santarém, PA, Brazil
}

\begin{abstract}
The aim of this work was to study the effect of the microwave radiation on the thermal and spectroscopic features, as well as about arrangement (order-disorder) and morphological properties, of the layered manganese oxide with birnessite-type structure. The route employed to obtain Na-birnessite matrix was redox precipitation. The products were characterized by X-ray diffraction, thermal analysis (TG-DTG-DSC), infrared (FTIR) and Raman spectroscopy, scanning electron microscopy (SEM) and nitrogen adsorption-desorption technique. The results showed that microwave radiation influenced in a short time (5 min) the octahedral ordering of birnessite, as well as in increasing the crystallite size. Thermal analysis showed that the thermal behavior of the lamellar matrix was different from that of birnessite under microwave radiation. After microwave-assisted hydrothermal treatment, FTIR and Raman spectroscopy investigations were used to differentiate ordered and disordered birnessites. Otherwise, there were no changes in SEM morphology of the lamellar-type phases, but the particle size changed.

Keywords: synthesis, microwave radiation, birnessite, thermal analysis, spectroscopy.
\end{abstract}

Resumo

No presente trabalho, apresenta-se um estudo da influência da radiação micro-ondas nas propriedades térmica e espectroscópica, assim como estrutural (ordem-desordem) e morfológica, de óxido de Mn estruturado em camada tipo Na-birnessita. A rota empregada para obtenção da matriz lamelar foi a precipitação redox. Os produtos foram caracterizados por difração de raios $X$, análise térmica (TG-DTG-DSC), espectroscopia de infravermelho (FTIR) e Raman, microscopia eletrônica de varredura e técnica de adsorção-dessorção de $\mathrm{N}_{2}$. Os resultados mostraram que a radiação por micro-ondas influenciou em um curto tempo (5 min) no ordenamento das folhas octaédricas de birnessita, assim como no aumento de tamanho de cristalito. Medidas de análise térmica revelaram que o comportamento termal da matriz lamelar birnessita foi diferente em relação à birnessita irradiada por microondas. Após tratamento por radiação de micro-ondas, estudos por espectroscopias FTIR e Raman foram usadas para diferenciar birnessita ordenada de desordenada. A morfologia em placas dos produtos envolvidos não sofreu mudança após radiação por micro-ondas, mas o tamanho das partículas alterou.

Palavras-chave: síntese, radiação micro-ondas, birnessita, análise termal, espectroscopia.

\section{INTRODUCTION}

In the last years, new chemical synthesis techniques have been developed aiming the reduction of energy consumption by decreasing the temperature and time of chemical reactions [1]. These novel techniques include the sonochemical [2], solution combustion [3] and hydrothermal [4] synthesis. Another approach towards energy reduction and particle size is the combination of two or more unconventional and novel synthesis techniques, such as the use of microwave energy, giving rise to new microwave-assisted synthesis methods $[5,6]$. The microwave-assisted hydrothermal (MAH)

* (D) https://orcid.org/0000-0002-0507-8662 synthesis of inorganic metal oxides has been intensified as a result of the advantages of this method in the production of nanometric materials (superconductors, catalysts, adsorbents, sensors, magnetic and ceramic materials) with controlled morphologies (nanowires, nanorods, nanofibers, etc.) among which are: rapid heating at the reaction temperature and high rates of reactive crystallization with the elimination of undesirable metastable phases [7-10]. During microwave radiation, the heating mechanisms involved are dipolar polarization and/or ionic conduction as a result of the interactions of dielectric materials (liquid and solids) with the microwave electromagnetic field. The ability of a material or reaction medium to convert electromagnetic energy into heat at a given frequency and temperature is 
related to the loss tangent $(\tan \delta)$, which relates the dielectric constant of the material ( $\varepsilon ")$ and the dielectric loss factor $\left(\varepsilon^{\prime}\right)$. Therefore, a material with high tand couples well with the microwave field, leading to rapid heating [11].

Manganese dioxide $\left(\mathrm{MnO}_{2}\right)$ is an important functional oxide that has excellent properties with wide applications in catalysis, ionic exchange, adsorption, electrochemistry, molecular sieves, magnetic and rechargeable batteries [12]. In recent years, the synthesis of $\mathrm{MnO}_{2}$ based on $\mathrm{MnO}_{6}$ octahedra with the formation of layered and tunnel-type structures with nanometric size, different morphologies and different crystallographic forms $(\alpha, \beta, \gamma, \delta$ and $\varepsilon)$ has received significant attention because of the unique properties that these structures present when cations $\mathrm{K}^{+}, \mathrm{Na}^{+}, \mathrm{H}^{+}$, and $\mathrm{Li}^{+}$ are intercalated in the structure [13]. In literature, there are few papers on MAH synthesis of lamellar materials of the Mn group with birnessite-like structure, despite the excellent properties and applications of these materials. One of the first papers was published in 2008, in which monoclinic birnessite-type material after microwave application was synthesized [14]. Other studies reported the synthesis of crystalline nanospheres of monoclinic birnessite $\left(\mathrm{Bir}-\mathrm{MnO}_{2}\right)$ with excellent electrochemical performance as a material for supercapacitor electrodes [15] and the influence of the $\mathrm{pH}$ of the medium on the morphology, crystallinity and the composition of crystalline phases in the MAH synthesis of $\mathrm{MnO}_{2}[16,17]$. In the paper herein, we investigated the influence of the crystallization time on the synthesis of sodium birnessite through microwave-assisted hydrothermal (MAH) treatment and its influence on the spectroscopic and thermal properties of the materials obtained.

\section{MATERIALS AND METHODS}

Synthesis route: the layered octahedral manganese oxide (lamellar precursor) was prepared by redox precipitation method as described in [13]. A solution of $0.3 \mathrm{~mol} / \mathrm{L}$ $\mathrm{MnNO}_{3} \cdot 6 \mathrm{H}_{2} \mathrm{O}$ (Merck) was poured into $0.6 \mathrm{~mol} / \mathrm{L} \mathrm{NaOH}$ (Merck, 99\% purity) and $10 \mathrm{~mL}$ of $3 \% \mathrm{H}_{2} \mathrm{O}_{2}$ (Isofar) mixed solutions. After stirring at room temperature for $24 \mathrm{~h}$, a dark precipitate was obtained, washed, air-dried for $6 \mathrm{~h}$ and named as BNa. The effect of time on microwave-assisted hydrothermal treatment of the birnessite phase $(\mathrm{BNa})$ was studied at 5, 10, 20, 40 and $80 \mathrm{~min}$. The products were filtered, washed, dried at $60^{\circ} \mathrm{C}$ overnight, and named $\mathrm{BNa}$ MO-05, BNa-MO-10, BNa-MO-20, BNaMO-40 and BNaMO-80, respectively. The microwave oven (Panasonic, Piccolo NN-ST357WRP) with pressure inside the reactor of $3 \mathrm{kgf} / \mathrm{cm}^{2}$ at $140{ }^{\circ} \mathrm{C}$ was employed to synthesis the materials.

Characterizations: the obtained solids were characterized by X-ray diffraction (XRD) in a PANalytical X'Pert PRO (MPD PW 3040/60) diffractometer with $\theta / \theta$ geometry and 1D pixel detector, monochromatic radiation $\mathrm{K} \alpha_{1}(\lambda=1.540598 \AA)$ of the copper tube. The records were collected in the $10-55^{\circ}(2 \theta)$ angular range. In order to identify the crystalline phases, the HighScore Plus software and the 3.0 JCPDS-ICDD database were used. The thermal behavior of the obtained solids was studied by thermogravimetric analysis (TG) and differential scanning calorimetry (DSC) at a heating rate of $5{ }^{\circ} \mathrm{C} / \mathrm{min}$, between 25 and $1025^{\circ} \mathrm{C}$, in a thermal analyzer Netzsch STA 449. The morphology was investigated in a Zeiss Supra 35 field emission gun scanning electron microscope (FEG-SEM), with an operating voltage of $5 \mathrm{kV}$ and a chamber pressure of $10^{-6} \mathrm{~Pa}$. The specific surface area of the birnessite powders was determined by the $\mathrm{N}_{2}$ adsorption-desorption method using the BET equation for the calculation of the area in a Quantachrome NOVA 2200 equipment. The samples were oven-dried for $24 \mathrm{~h}$ at $80^{\circ} \mathrm{C}$ and degassed under vacuum for $1 \mathrm{~h}$ at $150{ }^{\circ} \mathrm{C}$. The characterization of the solids by Fourier-transform infrared spectroscopy (FTIR) was performed on a Nicolet Nexus 470 spectrometer, in the range between 4000 and $400 \mathrm{~cm}^{-1}$ in the absorbance mode. Samples were prepared with a sample $/ \mathrm{KBr}$ ratio ranging from $3 \%$ to $5 \%$ and pressed into pellets. The Raman spectroscopy measurements were performed on a Horiba iH550 Raman spectrometer. The records were collected in the range between 70 and $1100 \mathrm{~cm}^{-1}$, during $60 \mathrm{~s}$ for each measurement, and a HeNe laser with a wavelength of $632.8 \mathrm{~nm}$ was used. A 100x objective Olympus lens was used to focus the beam on the sample. The signal dispersion was first performed in the entrance slit (with an aperture of $300 \mu \mathrm{m}$ ), and then in a diffraction grating of 1800 lines $/ \mathrm{mm}$. The signal was collected on a CCD detector thermallycooled by Peltier.

\section{RESULTS AND DISCUSSION}

Fig. 1 shows the XRD patterns of $\mathrm{MnO}_{2}$ lamellar solids obtained in the synthesis. For the BNa sample (without MAH), XRD peaks around 12.5, 25 and $36.5^{\circ}(2 \theta)$ were observed and related to the (001), (002) and (003) basal planes of the monoclinic birnessite (C2/m; PDF 043-1456), with an interlamellar spacing of $7.2 \AA$. The low intensity of $00 l$ XRD peaks revealed low crystallinity and high structural disorder degree of octahedral $\mathrm{MnO}_{6}$ sheets in this starting material. After microwave radiation treatment, the XRD peaks were gradually higher in intensity along with the increase of synthesis time, and the BNa-MO-40 and BNa-MO-80 samples presented the most well-defined X-ray diffraction patterns. Thus, the MAH treatment of the $\mathrm{BNa}$ sample favored the ordering of the sheets up to $40 \mathrm{~min}$. In addition, Table I also shows that the values of full width at half maximum (FWHM) decreased from $0.91^{\circ}$ (BNa) to $0.24^{\circ}$ (BNa-MO-40), indicating that the crystallinity degree of the obtained materials also increased as the treatment time raised. A value of $0.24^{\circ}$ (FWHM), with crystallite size of $35.97 \mathrm{~nm}\left(\mathrm{~d}_{001}=7.10 \AA\right)$, could also be observed for BNaMO-80 sample (80 min MAH), suggesting a mild structural disorder.

As observed before (Fig. 1 and Tables I and II), crystalline materials of nanometric dimensions were synthesized by only $5 \mathrm{~min}$ of $\mathrm{MAH}$, thus reducing the reaction time of days to minutes, to obtain layered manganese oxide phase. This decrease of the reaction time could be explained by 


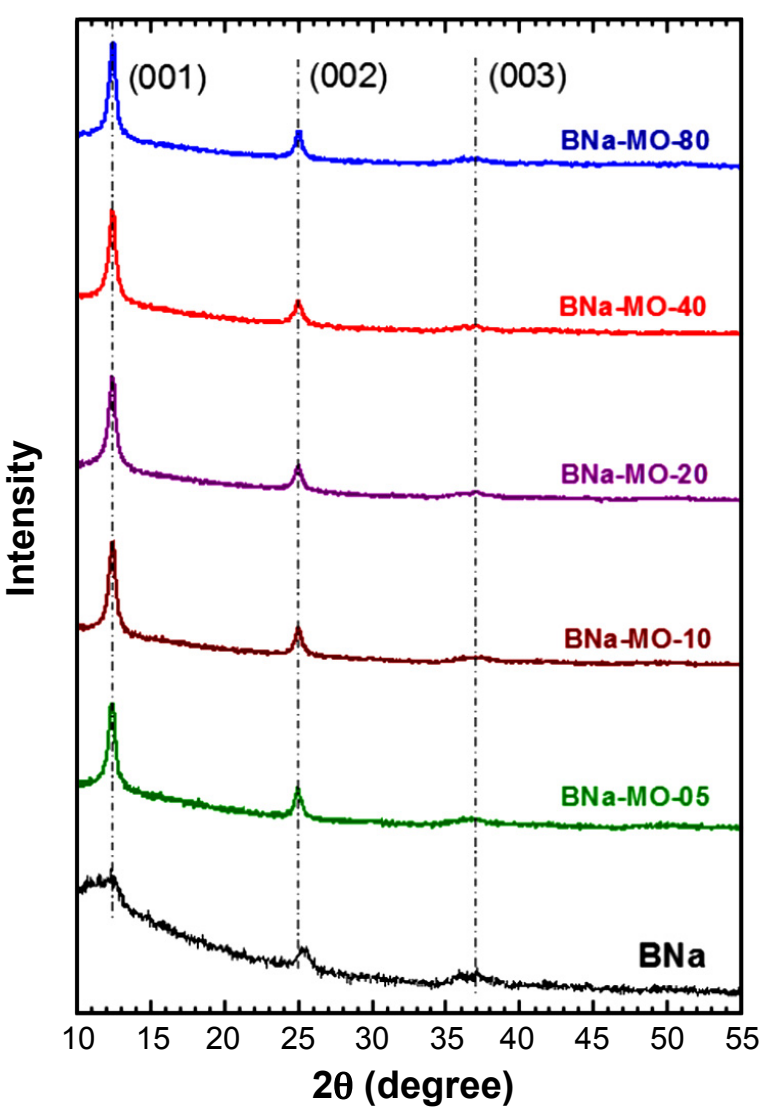

Figure 1: XRD patterns of BNa, BNaMO-05, BNaMO-10, BNaMO-20, BNaMO-40 and BNaMO-80 samples.

[Figura 1: Padrões de DRX das amostras BNa, BNaMO-05, BNaMO-10, BNaMO-15, BNaMO-20, BNaMO-40 e BNaMO-80.]

Table I - Values of full width at half maximum (FWHM), peak intensity (I), and crystallite size (CS) of investigated samples.

[Tabela I - Valores de largura à meia altura (FWHM), intensidade de pico (I) e tamanho de cristalito (CS) das amostras investigadas.]

\begin{tabular}{ccccc}
\hline Sample & $\begin{array}{c}\mathrm{d}_{(001)} \\
(\AA)\end{array}$ & FWHM & $\begin{array}{c}\mathrm{I}_{(001)} \\
(\text { count/s })\end{array}$ & $\begin{array}{c}\text { CS* } \\
(\mathrm{nm})\end{array}$ \\
\hline BNa & 7.20 & $0.91^{\circ}$ & 695 & 11.58 \\
BNa-MO-05 & 7.16 & $0.58^{\circ}$ & 1355 & 15.00 \\
BNa-MO-10 & 7.14 & $0.57^{\circ}$ & 1876 & 15.55 \\
BNa-MO-20 & 7.12 & $0.31^{\circ}$ & 2348 & 26.51 \\
BNa-MO-40 & 7.10 & $0.24^{\circ}$ & 3761 & 35.53 \\
BNa-MO-80 & 7.10 & $0.24^{\circ}$ & 3726 & 35.97 \\
\hline
\end{tabular}

* - calculated by Scherrer equation using Data Viewer 1.4 (Panalytical) software from reflection (001).

the interaction of the microwaves with manganese oxide $\left(\mathrm{Mn}^{4+}\right.$ and $\left.\mathrm{Mn}^{2+}\right)$ and water molecules, materials with high dielectric constant that transferring heat to reaction mixture increased the rate of effective collisions leading to faster and more homogeneous nucleation [9]. The formation mechanism of layered $\mathrm{MnO}_{2}$ (flowers-like morphology) during the hydrothermal process has been studied by several authors [21,22] and it is established that dissolutionnucleation-crystallization are the main events involved in the crystal growth in these materials. Based on these results, it is possible to believe that MAH method has a similar mechanism $[23,24]$ and can be described as follow: i) after mixing of the soluble precursors $\mathrm{Mn}\left(\mathrm{NO}_{3}\right)_{2}, \mathrm{NaOH}$ and $\mathrm{H}_{2} \mathrm{O}_{2}$ at room temperature the formation of a black amorphous $\mathrm{MnO}_{2}$ precipitate take place in a short time by a redox reaction in aqueous media, yielding a large number of nuclei according to:

$\mathrm{Mn}\left(\mathrm{NO}_{3}\right)_{2}+2 \mathrm{NaOH}+\mathrm{H}_{2} \mathrm{O}_{2} \rightarrow \mathrm{MnO}_{2}+2 \mathrm{NaNO}_{3}+2 \mathrm{H}_{2} \mathrm{O}$

ii) smaller particles dissolve while the bigger ones grow into sheet-like, with a layered crystal structure by a general Ostwald ripening mechanism [18-25]; iii) the high polarity of the water molecules and the $\mathrm{Mn}^{2+}$ ions present in aqueous solution when irradiated by the electric field of the microwaves release energy by two mechanisms, dipole rotation (dipole polarization) and ionic conduction, respectively, thus generating a considerable amount of energy which contributes to the heating, accelerating the effective collisions between the molecules of reagents and solvents improving consequently the nucleationcrystallization processes [26].

Table II - Literature data of microwave-assisted hydrothermal treatment of $\mathrm{MnO}_{2}$ to yield birnessite.

[Tabela II - Dados da literatura de tratamento hidrotérmico assistido por micro-ondas de $\mathrm{MnO}_{2}$ para obtenção de birnessita].

\begin{tabular}{cccc}
\hline $\begin{array}{c}\text { Time } \\
(\mathrm{min})\end{array}$ & $\begin{array}{c}\text { Temperature } \\
\left({ }^{\circ} \mathrm{C}\right)\end{array}$ & Phase & Ref. \\
\hline 30 & 160 & $\delta-\mathrm{MnO}_{2}$ - birnessite & {$[18]$} \\
30 & 75 & $\delta-\mathrm{MnO}_{2}-$ birnessite & {$[15]$} \\
25 & 100,140 & $\delta-\mathrm{MnO}_{2}-$ birnessite & {$[19]$} \\
20 & 170 & $\delta-\mathrm{MnO}_{2}-$ birnessite & {$[16]$} \\
8 & 90,120, & $\delta-\mathrm{MnO}_{2}-$ birnessite & {$[20]$} \\
& 150,170 & & \\
5 & 140 & $\delta-\mathrm{MnO}_{2}-$ birnessite & $*$ \\
\hline
\end{tabular}

* - this study.

The FTIR spectra of the birnessite-type materials are presented in Fig. 2. For BNa, bands around 3352, 3430, 3340 and $1610 \mathrm{~cm}^{-1}$ were identified and related to the stretching and bending vibrations of water molecules and interlayer hydroxyl groups. After MAH treatment, there was a remarkable displacement of these FTIR bands to $\sim 3425$ and $1630 \mathrm{~cm}^{-1}$, which could be related to the $\mathrm{H}_{2} \mathrm{O}$ and $\mathrm{OH}^{-}$ ordering in the structure. In addition, the bands between 900 $400 \mathrm{~cm}^{-1}$ caused by the stretching of $\mathrm{Mn}-\mathrm{O}$ bonds of $\mathrm{MnO}_{6}$ octahedral units $[27,28]$ were present at $637,590,510,475$ and $410 \mathrm{~cm}^{-1}$ for BNa and changed to 515,480 and $425 \mathrm{~cm}^{-1}$ of samples with ordered birnessite structure (BNa-MO-05, 
BNa-MO-10, BNa-MO-20, BNa-MO-40 and BNa-MO-80). It is noteworthy that the FTIR bands at 637 and $590 \mathrm{~cm}^{-1}$ present in the disordered structure $(\mathrm{BNa})$ disappeared in the ordered structure (BNa-MO-80).
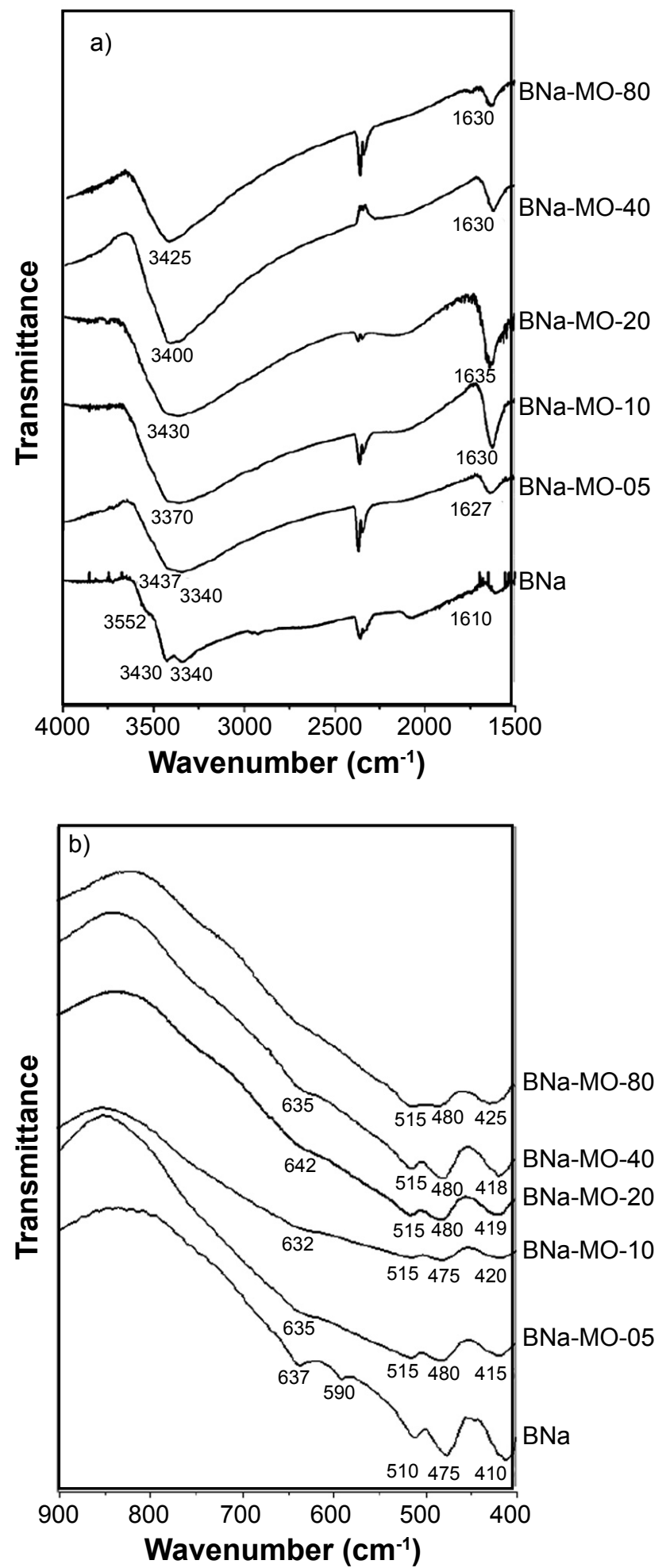

Figure 2: FTIR spectra of birnessite-type materials obtained before and after microwave-assisted hydrothermal (MAH) treatment.

[Figura 2: Espectros de infravermelho (FTIR) de birnessitas obtidas antes e depois do tratamento hidrotermal assistido por micro-ondas (MAH).]
Fig. 3 shows the Raman spectra (RS) of untreated and treated samples by MAH treatment. It is important to observe that manganese dioxides generally have low Raman activity [27], which is a difficulty in identifying and assigning bands by RS. Sodium birnessite, from the $\mathrm{C} 2 / \mathrm{m}$ monoclinic space group with $\mathrm{Z}=1$, presents 9 active Raman modes $\left(3 \mathrm{~A}_{\mathrm{g}}\right.$ and $\left.6 \mathrm{~B}_{\mathrm{g}}\right)$ and 12 active infrared modes $\left(4 \mathrm{~A}_{\mathrm{u}}\right.$ and $\left.8 \mathrm{~B}_{\mathrm{u}}\right)$ [14]. According to Fig. 3, all RS of the materials obtained by the MAH method had two high-frequency bands dominating the spectrum, with bands in the region of low frequency of low intensity. The low-frequency bands at $\sim 177$ and $294 \mathrm{~cm}^{-1}$ corresponded to the translational deviation of the $\left[\mathrm{MnO}_{6}\right]$ octahedrons and to the stretching modes of the $\mathrm{NaO}_{6}$ interlayer groups [14]. The high frequency bands at 576 and $643 \mathrm{~cm}^{-1}$ corresponded to the symmetrical stretching of the oxygen atoms with respect to the manganese atoms $v_{3}(\mathrm{Mn}-\mathrm{O})$ along the octahedral chains in the basal plane of $\left[\mathrm{MnO}_{6}\right]$ sheets, and stretching vibrations $\mathrm{v}_{2}(\mathrm{Mn}-\mathrm{O})$ perpendicular to the double chains of the $\left[\mathrm{MnO}_{6}\right]$ octahedron, respectively [29-31]. For untreated sample by MAH (BNa), the bands at 177 and $294 \mathrm{~cm}^{-1}$ were absent, while the Raman band around $576 \mathrm{~cm}^{-1}$ could be identified and related to the disordered birnessite.

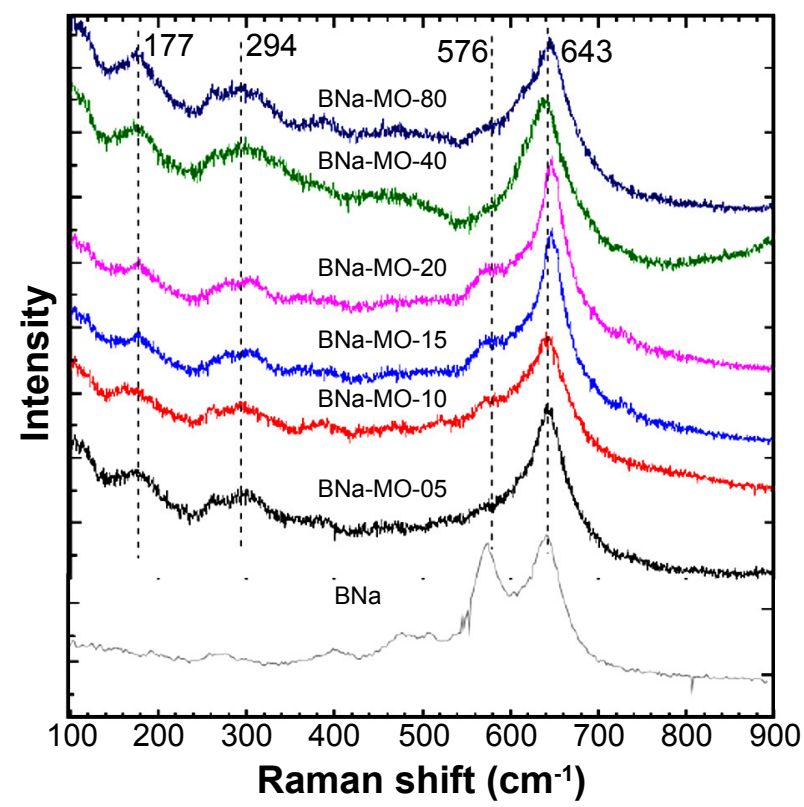

Figure 3: Raman spectra of birnessite-type materials. [Figura 3: Espectros Raman das birnessitas obtidas.]

The thermal behavior of $\mathrm{BNa}$, BNaMO-05, BNaMO-40 and BNa-MO-80 samples investigated by TG-DSC-DTG analysis is shown in Fig. 4. Fig. 4a shows that BNa sample presented six thermal events in the studied temperature range, one exothermic event and 5 endothermic events. In the TG curve (Fig. 4b), a total weight loss of $21.17 \%$ was identified. In the range of $25-225^{\circ} \mathrm{C}$, two endothermic peaks at 66 and $151^{\circ} \mathrm{C}$ were observed and associated with the loss of adsorbed and interlamellar water of birnessite [29]. At $530^{\circ} \mathrm{C}$, an exothermic peak related to changes in the crystalline structure 

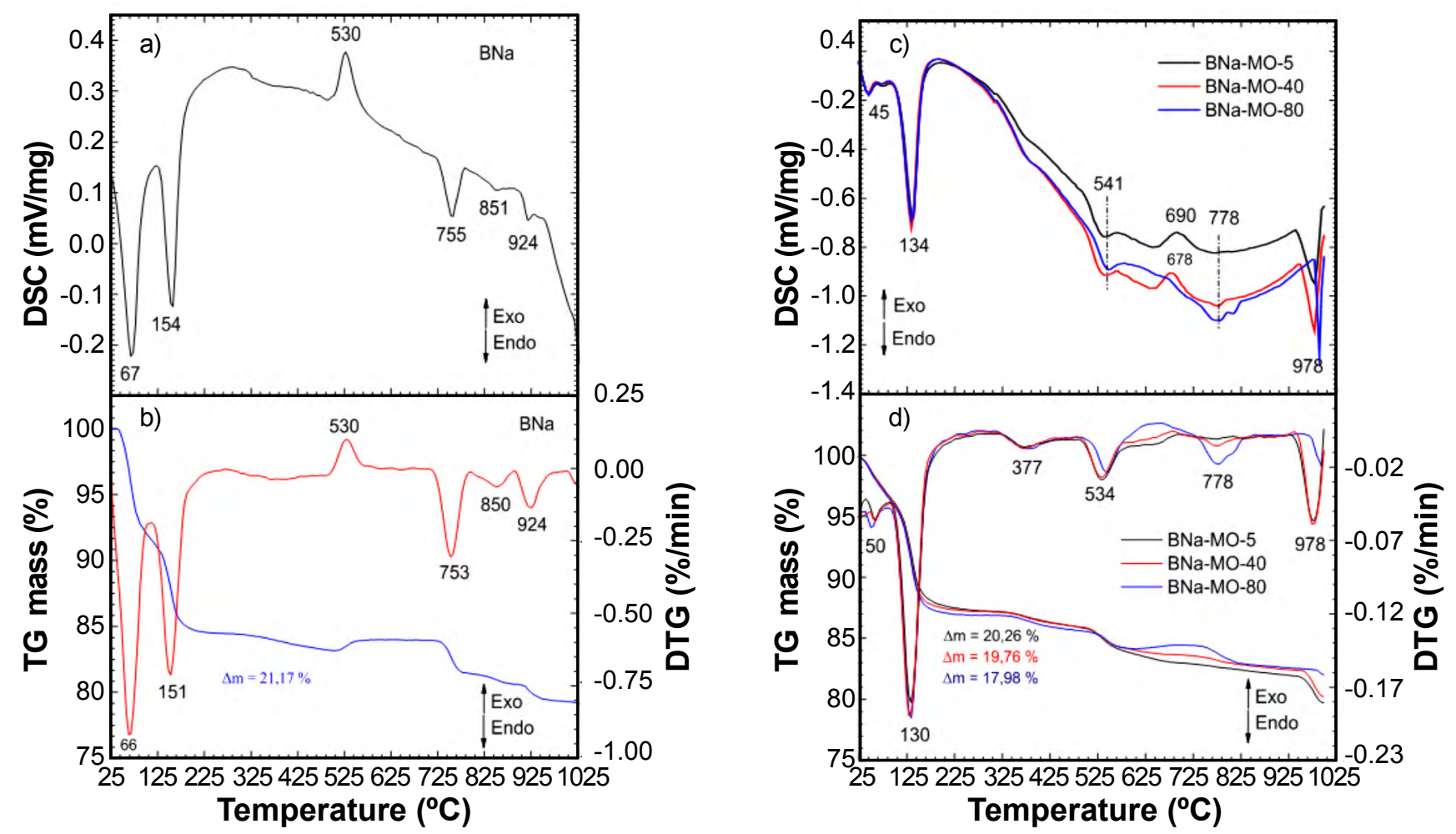

Figure 4: DSC-TG-DTG curves of BNa (a,b), BNaMO-05, BNaMO-40 and BNa-MO-80 (c,d) samples.

[Figura 4: Curvas de DSC-TG-DTG das amostras BNa (a,b), BNaMO-05, BNaMO-40 e BNa-MO-80 (c,d).]

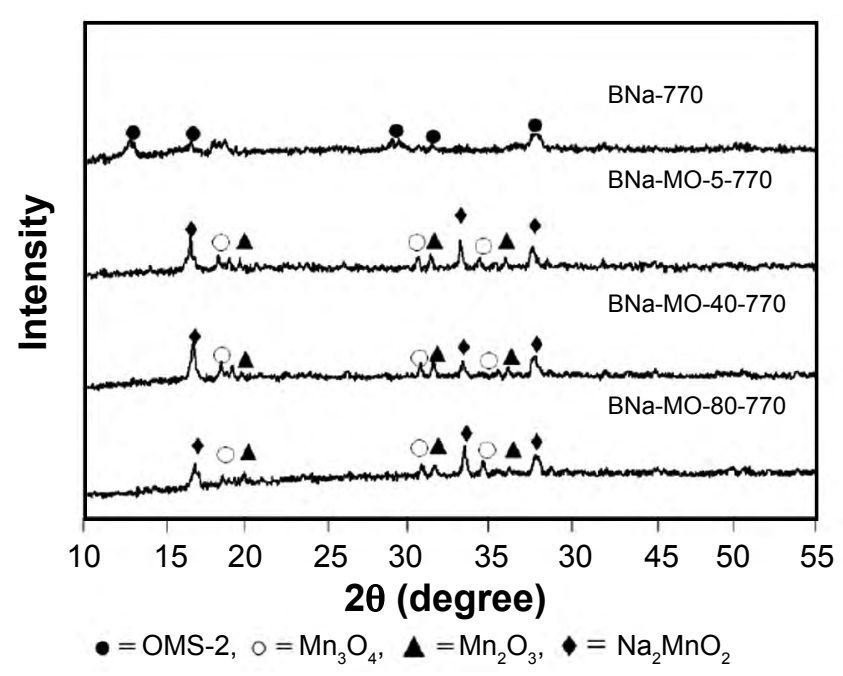

Figure 5: X-ray diffraction patterns of $\mathrm{BNa}$, BNa-MO-05, BNaMO-40 and BNaMO-80 samples heated at $770{ }^{\circ} \mathrm{C}$.

[Figura 5: Padrões de DRX das amostras BNa, BNa-MO-05, BNaMO-40 e BNaMO-80 aquecidas a $770{ }^{\circ} \mathrm{C}$.].

of the layered material for tunnel-type structure (OMS-2) was observed [30]. Above this temperature, the presence of exothermic peaks around 750 and $850{ }^{\circ} \mathrm{C}$ was attributed to the gradual release of oxygen from the $\mathrm{MnO}_{6}$ octahedra and to the conversion of $\mathrm{Mn}^{4+}$ into $\mathrm{Mn}^{3+}$ [31], suggesting that OMS-2 structure remained stable at $900{ }^{\circ} \mathrm{C}$. Above this temperature $\left(\sim 924{ }^{\circ} \mathrm{C}\right)$, another endothermic peak was detected as a result of the transformation of the OMS-2 structure into $\mathrm{Mn}_{2} \mathrm{O}_{3}$ and $\mathrm{Mn}_{3} \mathrm{O}_{4}$. For the samples treated with microwave radiation, it was observed that these samples presented similar thermal behavior among each other, but quite different from the starting material (BNa). That was due to the fact that the exothermic transformation was not observed in these materials at around $530{ }^{\circ} \mathrm{C}$; instead, that was observed at $680{ }^{\circ} \mathrm{C}$ (Figs. 4c and 4d) for the BNa-MO-05, BNa-MO-40 and BNa-MO-80, indicating complex thermal decomposition of Na-birnessite to $\mathrm{Mn}_{2} \mathrm{O}_{3}, \mathrm{Mn}_{3} \mathrm{O}_{4}$ and $\mathrm{NaMnO}_{2}$-type phases, which suggested that the microwave radiation in the proposed experimental conditions inhibited the tunneling and formation of OMS2. To complement the TG-DSC-DTG results, X-ray diffraction investigation of the samples $\mathrm{BNa}, \mathrm{BNa}-\mathrm{MO}-05$, BNaMO-40 and BNaMO-80 heated at high temperature $\left(\sim 770{ }^{\circ} \mathrm{C}\right)$ was performed to monitoring the major thermal transformations of layered-type materials (Fig. 5). After calcination of $\mathrm{BNa}$ at $770{ }^{\circ} \mathrm{C}$, the XRD pattern showed the formation of tunnel manganese oxide with OMS-2 structure (PDF 042-1347), thus confirming the tunneling of Na-birnessite into Na-OMS-2. At the same temperature, XRD patterns recorded for BNa-MO-05-770, BNaMO-40-770 and BNaMO-80-770 were due to $\mathrm{Mn}_{2} \mathrm{O}_{3}$ (PDF 031-0825), $\mathrm{Mn}_{3} \mathrm{O}_{4}$ (PDF 024-0734) and $\mathrm{NaMnO}_{2}$ (PDF 025-0845) phases.

Comparative SEM images of the birnessite-type materials untreated (BNa) and treated (BNa-MO-05 and BNa-MO-80) by MAH are shown in Fig. 6. The SEM micrograph of BNa (Fig. 6a) revealed the intergrowth of various platy-shaped particles of Na-birnessite, as already reported [15, 19, 31, 32]. The presence of the similar morphology in the treated 

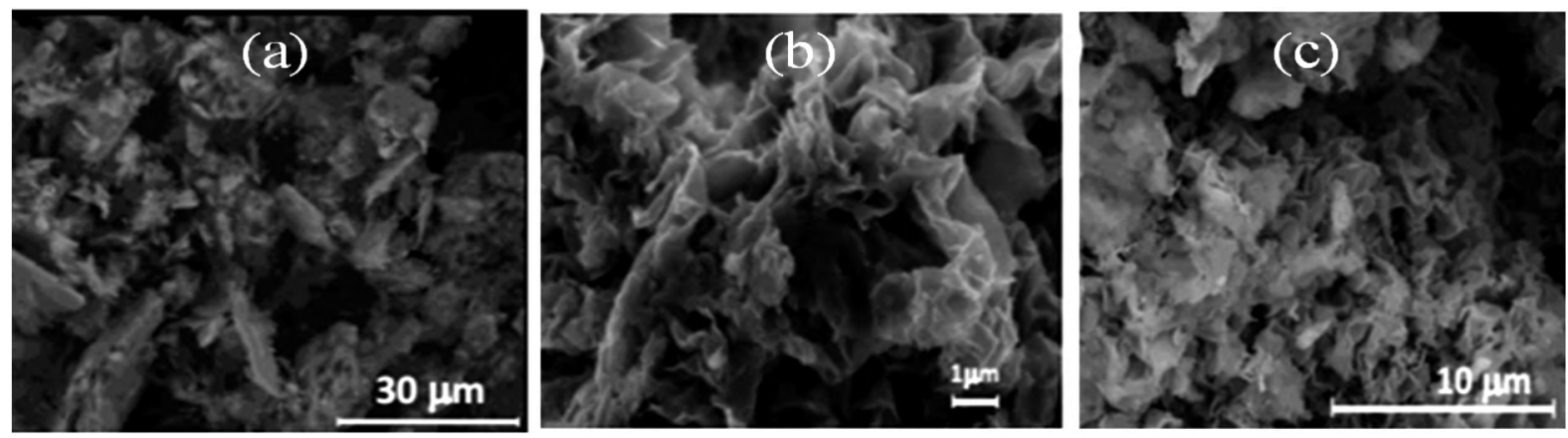

Figure 6: SEM micrographs of BNa (a), BNa-MO-05 (b) and BNa-MO-80 (c).

[Figura 6: Micrografias de MEV das amostras BNa (a), BNa-MO-05 (b) e BNa-MO-80 (c).]

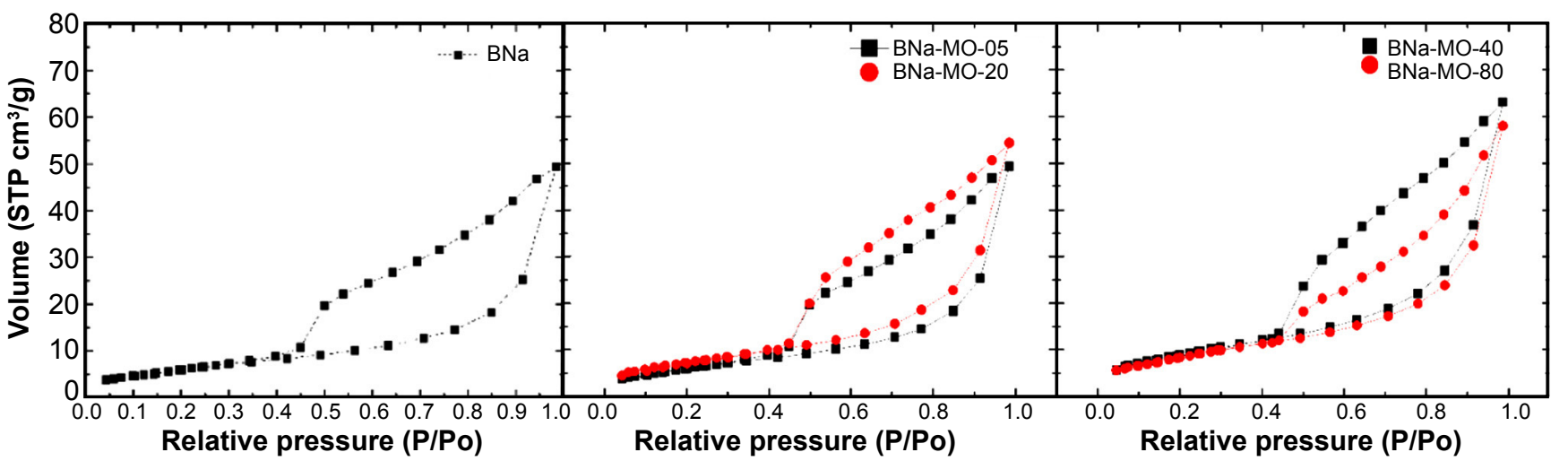

Figure 7: Adsorption isotherms of BNa, BNa-MO-05, BNa-MO-20, BNa-MO-40, and BNa-MO-80.

[Figura 7: Isotermas de adsorção de BNa, BNa-MO-05, BNa-MO-20, BNa-MO-40 e BNa-MO-80.]

Table III - Textural properties of untreated and treated samples by MAH.

[Tabela III - Propriedades texturais das amostras não tratada e tratadas por MAH.]

\begin{tabular}{cccc}
\hline Sample & SSA $\left(\mathrm{m}^{2} / \mathrm{g}\right)$ & PS $(\mathrm{nm})$ & $\mathrm{TPV}\left(\mathrm{cm}^{3} / \mathrm{g}\right)$ \\
\hline BNa & 43.86 & 6.91 & 0.267 \\
BNa-MO-05 & 23.24 & 6.57 & 0.076 \\
BNa-MO-10 & 22.49 & 6.53 & 0.073 \\
BNa-MO-20 & 27.08 & 6.20 & 0.084 \\
BNa-MO-40 & 33.91 & 5.75 & 0.097 \\
BNa-MO-80 & 32.17 & 5.58 & 0.089 \\
\hline
\end{tabular}

SSA - specific surface area; $P S$ - pore size; TPV - total pore volume.

BNa-MO-05 and BNa-MO-80 samples (Figs. 6b and 6c) suggested that MAH did not affect the original morphology. On the other hand, the size of the original BNa particles $(\sim 30 \mu \mathrm{m})$ was reduced with the treatment by MAH, after 5 $\min (\sim 5 \mu \mathrm{m})$ and $80 \mathrm{~min}(15 \mu \mathrm{m})$, as verified in the samples BNa-MO-05 and BNa-MO-80 (Fig. 6).

The adsorption-desorption isotherms of both the matrix and the microwave treated samples were characterized and shown in Fig. 7. The adsorption isotherms of all samples showed similar shapes, being classified as type III, with type $\mathrm{H} 3$ hysteresis loop in a relative pressure range $\left(\mathrm{P} / \mathrm{P}_{0}\right)$ of 0.5 to 1.0. These isotherms are known for their slow initial adsorption as a result of poor adsorption forces. They do not exhibit any limiting adsorption at high speeds and are characteristic of materials with aggregates of particles of irregular porosity [33]. The value of the specific surface area, pore size and total pore volume of the products involved in this study were also investigated and are given in Table III. According to the results obtained, a BET surface area of $43.86 \mathrm{~m}^{2} / \mathrm{g}$ was obtained for $\mathrm{BNa}$, which presented a pore size of $6.91 \mathrm{~nm}$ and total pore volume of $0.267 \mathrm{~cm}^{3} / \mathrm{g}$. After 5 min (BNa-MO-05) of MAH treatment time, specific surface area $\left(23.24 \mathrm{~m}^{2} / \mathrm{g}\right)$, pore size $(6.57 \mathrm{~nm})$ and total pore volume $\left(0.076 \mathrm{~cm}^{3} / \mathrm{g}\right)$ values were markedly reduced, and this reduction was maintained over $80 \mathrm{~min}$ of MAH treatment (BNa-MO-80). Zhang et al. [34] synthesized birnessite by MAH and reported specific surface area value $\left(50 \mathrm{~m}^{2} / \mathrm{g}\right)$ and total pore volume $\left(0.21 \mathrm{~cm}^{3} / \mathrm{g}\right)$ higher than observed here, while pore size value was lower $(3.88 \mathrm{~nm})$.

\section{CONCLUSIONS}

Low ordered birnessite-type material was successfully synthesized by the redox-precipitation route and irradiated by microwave radiation. According to the XRD patterns of the samples treated by MAH (microwave-assisted hydrothermal synthesis), the degree of ordering became higher than that in the lamellar matrix without radiation. Through the thermal analyses by TG-DTG-DSC, it was observed that microwave irradiation affected the transformation of layered manganese oxide into tunnel structure (OMS-2). The Raman and FTIR spectroscopy proved to be quite useful to differentiate ordered-disordered birnessite-type materials. 
The morphology of products was not affected by microwave irradiation.

\section{ACKNOWLEDGMENTS}

The authors are grateful to funding agencies FAPEMA (Project No. 01235/2016), CAPES (master's degree scholarship for T.C.C. Lavra and project funding \# 88881.160695), and CNPQ (project 420169/2016-4).

\section{REFERENCES}

[1] J.M. Patete, X. Peng, C. Koenigsmann, Y. Xu, B. Karn, S.S. Wong, Green Chem. 13 (2011) 482.

[2] A.E. Baranchikov, A.S. Shaporev, V.K. Ivanov, Y.D. Tret'yakov, Inorg. Mater. 43, 1 (2007) 35.

[3] A. Varma, A.S. Mukasyan, A.S. Rogachev, K.V. Manukyan, Chem. Rev. 116 (2016) 14493.

[4] S. Feng, G. Li, in Modern Inorg. Synth. Chem., R. Xu, W. Pang, Q. Huo (Eds.), 2 nd ed., Elsevier, Oxford (2017) 73. [5] C. Leonelli, S. Komarneni, Inorganics 3 (2015) 388.

[6] L. Yan, S. Zhao, X. Wang, Y. Li, Z. Gao, B. Zhang, M. Cao, Y. Qin, ACS Appl. Mater. Interfaces 9 (2017) 11116.

[7] M. Tsuji, M. Hashimoto, Y. Nishizawa, M. Kubokawa, Chem. Eur. J. 11 (2005) 440.

[8] G.A. Tompsett, W.C. Conner, K.S. Yngvesson, Chemphyschem 2, 7 (2007) 296.

[9] M. Baghbanzadeh, L. Carbone, P.D. Cozzoli, C.O. Kappe, Angew. Chem. Int. Ed. 50 (2011) 11312.

[10] H. Zhou, Y. Miao, J. Chen, X. Chen, F. He, D. Ma, J. Mater. Sci.: Mater. Electron. 25 (2014) 2470.

[11] J. Prado-Gonjal, E. Morán, An. Quím. 107 (2011) 129.

[12] H.A. Pan, O. Ghodbane, Y.T. Weng, H. Sheu, J.F. Lee, F. Favier, N.L. Wu, J. Electrochem. Soc. 162 (2015) 5106.

[13] Q. Feng, E.H. Sun, K. Yanagisawa, N. Yamasaki, J. Ceram. Soc. Japan 105, 7 (1997) 564.

[14] A. Dias, R.G. Sá, M.C. Spitale, M. Athayde, V.S.T.
Ciminelli, Mater. Res. Bull. 43 (2008) 1528.

[15] B. Ming, J. Li, F. Kang, G. Pang, Y.Y. Zhang, L. Chen, J. Xu, X. Wang, J. Power Sources 198 (2012) 428.

[16] R.F. Korotkov, A.E. Baranchikov, O.V. Boytsova, V.K. Ivanov, Russ. J. Inorg. Chem. 60, 11 (2015) 1299.

[17] R.F. Korotkov, A.E. Baranchikov, A.E. Goldt, S.A. Kurzeev, O.V. Boytsova, V.K. Ivanovb, Russ. J. Inorg. Chem. 61 (2016) 129.

[18] Y. Li, J. Wang, Y. Zhang, M.N. Banis, J. Liu, D. Geng, R. Li, X. Sun, J. Colloid Interface Sci. 369 (2012) 123.

[19] P. Wang, Y.J. Zhao, L.X. Wen, J.F. Chen, Z.G. Lei, Ind. Eng. Chem. Res. 53 (2014) 20116.

[20] O.V. Boytsova, T.O. Shekunova, A.E. Baranchikov, Russ. J. Inorg. Chem. 60, 5 (2015) 546.

[21] X. Wang, Y. Li, Chem. Eur. J. 9 (2003) 5627.

[22] L.-C. Zhang, Z.-H. Liu, H. Ly, X. Thang, K. Ooi, J. Phys. Chem. C 111 (2007) 8418.

[23] Z. Ai, L. Zhang, F. Kong, H. Liu, W. Xing, J. Qiu, Mater. Chem. Phys. 111 (2008) 162.

[24] N. Xiu, Z.-H. Liu, J. Nanopart. Res. 11 (2009) 1107.

[25] L.-Y. Meng, B. Wang, M.-G. Ma, K.-L. Lin, Mater. Today 1-2 (2016) 63.

[26] V. Chikan, E. J. McLaurin, Nanomaterials 6 (2016) 85.

[27] C.M. Julien, M. Massot, C. Poinsignon, Spectrochim. Acta 60 (2004) 689.

[28] L. Kang, M. Zhang, Z.H. Liu, K. Ooi, Spectrochim. Acta 67 (2007) 864.

[29] M.A. Cheney, R. Jose, A. Banerjee, P.K. Bhowmik, S. Qian, J.M. Okoh, J. Nanomater. 2009 (2009) 940462.

[30] B.A.M. Figueira, R.S. Angélica, M.L Costa, J.M.R. Mercury, D. Biggemann, H. Pöllmann, Micropor. Mesopor. Mat. 179 (2013) 212.

[31] Q. Feng, H. Kanoh, Y. Miyai, K. Ooi, Chem. Mater. 7 (1995) 1722.

[32] S. Suib, Q. Zhang, J. Luo, Inorg. Chem. 39 (2000) 741.

[33] M. Jaroniec, M. Kruk, Chem. Mater. 13 (2001) 3169.

[34] X. Zhang, W. Miao, C. Li, X. Sun, K. Wang, Y. Ma, Mater. Res. Bull. 71 (2015) 111.

(Rec. 16/12/2018, Rev. 02/05/2019, Ac. 07/05/2019) 